\title{
A Study on the Correlation of Milk Yield of Cows with Seismicity and ULF Magnetic Field Variations
}

\author{
Masashi Hayakawa1,2, Tomokazu Asano1, Alexander Schekotov³, Hiroyuki Yamauchi4 \\ ${ }^{1}$ Hayakawa Institute of Seismo Electromagnetics, Co. Ltd., University of Electro-Communications (UEC) Incubation Center, Chofu, Japan \\ ${ }^{2}$ Advanced Wireless \& Communications Research Center, UEC, Chofu, Japan \\ ${ }^{3}$ Institute of Physics of the Earth, Russian Academy of Sciences, Moscow, Russia \\ ${ }^{4}$ Department of Human and Animal-Plant Relationships, Azabu University, Sagamihara, Japan \\ Email: hayakawa@hi-seismo-em.jp
}

How to cite this paper: Hayakawa, M., Asano, T., Schekotov, A. and Yamauchi, H. (2016) A Study on the Correlation of Milk Yield of Cows with Seismicity and ULF Magnetic Field Variations. Open Journal of Earthquake Research, 5, 206218.

http://dx.doi.org/10.4236/ojer.2016.54017

Received: October 13, 2016

Accepted: November 14, 2016

Published: November 17, 2016

Copyright $\odot 2016$ by authors and Scientific Research Publishing Inc. This work is licensed under the Creative Commons Attribution International License (CC BY 4.0).

http://creativecommons.org/licenses/by/4.0/

\begin{abstract}
A statistical study on the basis of one-year data of 2014 has been performed in order to find whether abnormal animal behavior is related with seismic activity and also whether the ULF (Ultra Low Frequency) electromagnetic radiation might be a possible sensory mechanism of abnormal animal behavior. Abnormal animal behavior has been studied with the use of digitally recorded milk yield of cows at Ibaraki Prefecture Livestock Station, and the ULF magnetic field changes have been studied with the data at a magnetic observatory of Kakioka. As the result of correlation analyses, clear responses are observed for both the milk yield of cows and ULF magnetic field changes (both ULF radiation (ULF emissions from the lithosphere) and ULF depression (as an indicator of lower ionospheric perturbations)) for most powerful and not distant earthquakes (EQs) with magnitude $>6$, that is, the milk yield of cows is found to exhibit a conspicuous depletion about 17 - 18 days before an EQ, though the correlation coefficient is not so big. Another important objective in this paper is to identify that ULF radiation is the main agent of abnormal behavior so that we have compared the temporal evolutions of milk yield of cows, ULF radiation and ULF depression for three major EQs. As a result, it is found that ULF radiation happens, at least, during the periods of abnormal depletion of milk yield of cows.
\end{abstract}

\section{Keywords}

Milk Yield of Cows, Correlation Analyses, Earthquake Prediction, ULF Radiation, ULF Depression 


\section{Introduction}

The prediction of an earthquake (EQ) (to be more exact, short-term EQ prediction) requires the presence of precursors of any kind [1], so that extensive studies have been carried out on the evolutions of pre-seismic parameters of different phenomena during the last few decades (see, e.g. [2]). These are 1) mechanical, 2) electromagnetic effects and 3) macroscopic phenomena. Mechanical effects include foreshock activity, pre-slip effect, etc. [2]. Then, it is recently agreed that electromagnetic phenomena do occur before EQs (e.g., [3]-[8]), which are considered to be very promising for short-time EQ prediction. Among various electromagnetic precursors, there already exist a few phenomena which are found to be statistically correlated with EQs. One typical example is ionospheric perturbations not only in the lower ionosphere using subionospheric VLF/ LF (Very Low Frequency/Low Frequency) propagation anomalies [9] but also in the upper F region using bottomside sounding anomalies [10]. Additionally, seismogenic ULF emissions have been observed prior to an EQ (e.g., [11] [12] [13]).

The topic of this paper is macroscopic phenomena which are mainly abnormal animal behavior [2]. Many examples are described in the literature [2] [14]-[24], together with the suggestion of possible sensory mechanisms of such abnormal animal behavior. Recently, though as a case study, Yamauchi et al. [25] have found, based on digitally recorded data, an abnormal decrease in milk yield of cows before the disastrous 2011 Tohoku EQ (M 9).

The large casualty of the latest 2011 March 11 Tohoku EQ accentuated urgent necessity of short-term EQ prediction, with emphasis on further extensive studies on precursors for different EQs. Yamauchi et al. [25] have found that the milk yield of cows is likely to be depleted before the EQ, which is based on the quantitative estimation of daily data of milk yield of cows, not on the anecdotal and retrospective data as in many earlier papers such as [2]. Also, Hayakawa [26] has suggested that the low frequency (or ULF/ELF (Extremely Low Frequency)) electromagnetic radiation might be closely related with abnormal animal behavior on the basis of comparisons of Rikitake's results with the recent records on the statistical data of different electromagnetic phenomena obtained during the last two decades. So the following physical parameters are treated in this paper: 1) milk yield of cows as the main parameter, 2) ULF magnetic field changes (ULF radiation/depression), and 3) seismicity, and we perform the correlation studies of different combinations of these parameters for a particular year of 2014. Finally, we compare extensively the temporal evolutions of those three parameters for the major three EQs, and we try to discuss the sensory mechanism of cows for EQs.

\section{Milk Yield of Cows}

The first important point we have to emphasize here is that we are not based on the conventional anecdotal records as in early studies, but on the scientific (or digitally recorded) data on animals.

The data on the milk yields of cows are obtained with the continuous observation at the Ibaraki Prefecture Livestock Experimental Station (geographic coordinates: 
$36.02^{\circ} \mathrm{N}, 140.12^{\circ} \mathrm{E}$ ) as shown in Figure 1 as a yellow rhombic (with abbreviation of IBR).

The number of cows at Ibaraki station is $30-37$ as indicated in our previous paper [25]. We have performed pre-processing of the signal, because we know some known factors decreasing the milk yield. That is, we have removed the conventional effect of the temperature-humidity index [27], which is used as an index of heat stress for cows [28] when they measure the milk yield once a day, by using a two-phased regression model. This residue in the milk yield of cows is studied here.

\section{Earthquakes (EQ) Treated in This Paper}

The first step consists in the choice of EQs. As for the EQ data, we have used seismic data from the ANSS (Advanced National Seismic System) Worldwide Earthquake Catalogue in such a way that they should provide at least noticeable response in the milk yield of cows and ULF radiation/depression. Additionally, the interval between EQs should be larger than the duration of the responses in order to have a possibility to separate

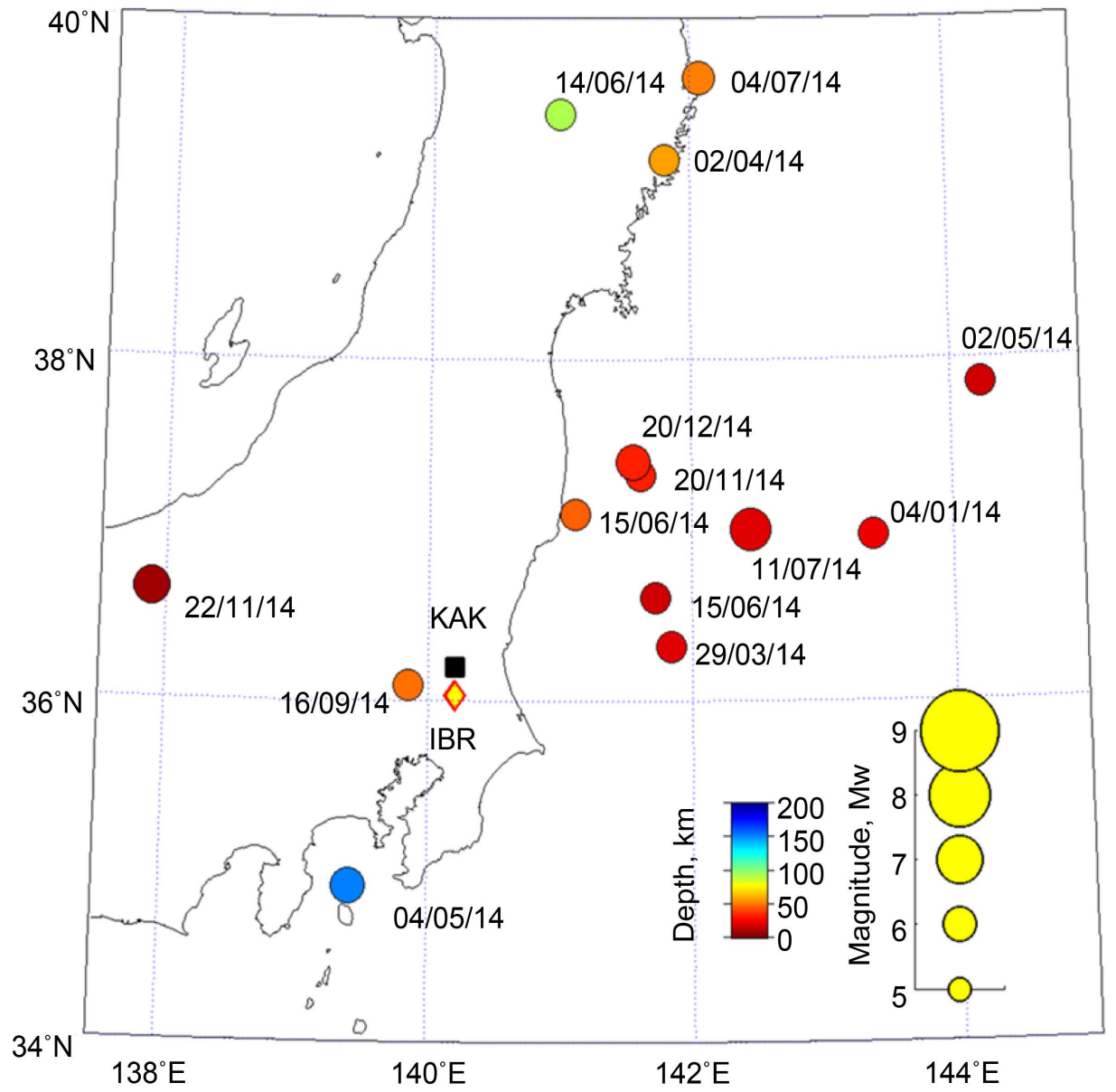

Figure 1. A map of EQs with $\mathrm{M}>5.5$ for all Kls (any distance). The size of a circle is proportional to the EQ magnitude, and the color indicates its depth. Also two stations, Ibaraki (IBR) station (for the milk yield of cows) and Kakioka (KAK) ULF station are plotted. 
the events. It was seen from the previous analyses [2] that EQs with $M<5$ do not generate any effect or abnormal animal behavior such as the milk yield of cows. So that, EQs both with $\mathrm{M}>5$ and with not so big distance (Kls > 5) were considered as the first stage, where Kls is considered as a local seismic index which is defined by Kls $=10^{0.75 \mathrm{M}}$ / $(\mathrm{R}+100)$ in Molchanov and Hayakawa [3] (M: EQ magnitude and R: epicentral distance (in $\mathrm{km}$ )). An EQ is significant at least for Kls $>1$. Figure 1 illustrates a map of the epicenters of EQs with $\mathrm{M}>5.5$ for all Kls. The size of a circle indicating an EQ is proportional to the EQ magnitude $(\mathrm{M})$, and its depth is indicated by the corresponding color. We estimate the maximum Kls for each day, and take it as the value for that day. So we will be able to have the time-series data for Kls to have the cross-correlation with those of any other parameter in the following.

\section{ULF Magnetic Field Data}

The ULF magnetic and Dst (geomagnetic activity) data were obtained from the site of World Data Center (WDC) for Geomagnetism, Kyoto. The data are given in IAGA (International Association of Geomagnetism and Aeronomy) 2000 format, in which the magnetic field is represented by four components: Horizontal $(\mathrm{H})$, declination $(\mathrm{D})$, vertical (Z), and total field (F).

We use ULF data available from one magnetic standard observatory belonging to JMA (Japan Meteorological Agency): Kakioka (KAK) as a black square in Figure 1. The sampling frequency of magnetometer at this ULF station is equal to $1 \mathrm{~Hz}$.

After performing band-pass filtering of the signals and calculation of their mean power, depression and radiation at different frequencies, we estimate magnitudes of the horizontal component $(\mathrm{H})$ and vertical component $(\mathrm{Z})$ at any particular frequency. In this paper, we pay attention not only to the conventional seismogenic ULF radiation from the lithosphere [11] [12], but also to the non-conventional depression of ULF horizontal $(\mathrm{H})$ component as an indicator of the lower ionospheric effect of downgoing ULF waves of magnetospheric origin [3] [29] [30].

As an indicator of ULF electromagnetic radiation from the lithosphere, Hayakawa et al. [31] have proposed a new parameter of $\mathrm{Z} / \mathrm{H}$ (called "polarization" as the ratio of power spectral densities of $\mathrm{Z}$ (vertical component) and $\mathrm{H}$ (horizontal component)), to distinguish precursory seismogenic radiation from other noises including the dominant space plasma waves. A recent paper by Currie and Waters [32] has confirmed that this parameter, $\mathrm{Z} / \mathrm{H}$ is a good indicator of seismogenic ULF emission. So we use an increase in this parameter to find out any seismogenic ULF radiation.

On the other hand, the depression of ULF $\mathrm{H}$ component which is a non-conventional new parameter though not so popular in the scientific society, has been found to be a good indicator of the precursory lower ionospheric perturbations of an EQ [29], because the main element of ULF H component is apparently of magnetospheric origin and those space plasma waves suffer from an additional effect when passing through the lower ionosphere perturbed prior to an EQ [29] [30] [33]. So that, the depression as the inverse of $\mathrm{H}$ power spectral density is extensively studied also in this paper. 


\section{Results of Comparisons among Milk Yield of Cows, Seismicity, and ULF Magnetic Field Variation}

Figure 2 illustrates the daily evolutions of various parameters during one particular year of 2014. The parameters are as follows; from the top, seismicity (Kls) (with $\mathrm{M}>5.5$ and $\mathrm{Kls}>5$ ), milk yield of cows, ULF radiation (polarization as the ratio of Z component to horizontal components, indicated by $\mathrm{R}$ (as ULF radiation) in the figure), and finally the depression of $\mathrm{H}$ component (Dep) as the inverse of the $\mathrm{H}$ component power [30]. After checking the spectra of the background at different frequencies, we have chosen a particular frequency range of $0.01-0.02 \mathrm{~Hz}$ in a selected local time of LT $=3 \mathrm{~h} \pm$ $1.5 \mathrm{~h}$ for both $\mathrm{R}$ and Dep because of minimum man-made interferences. The bottom five panels refer to the results of superimposed epoch analysis of lag-correlograms of different combinations of those parameters over the EQs with $\mathrm{M}>5.5$ and Kls $>5$ in the top panel of the figure. The left-most panel is the lag-correlogram of the milk yield of cows against Kls, in which 0 (day) on the abscissa indicates EQ day, and -(+) (days) means that the milk yield of cows shows some effect before (after) the EQ. This figure

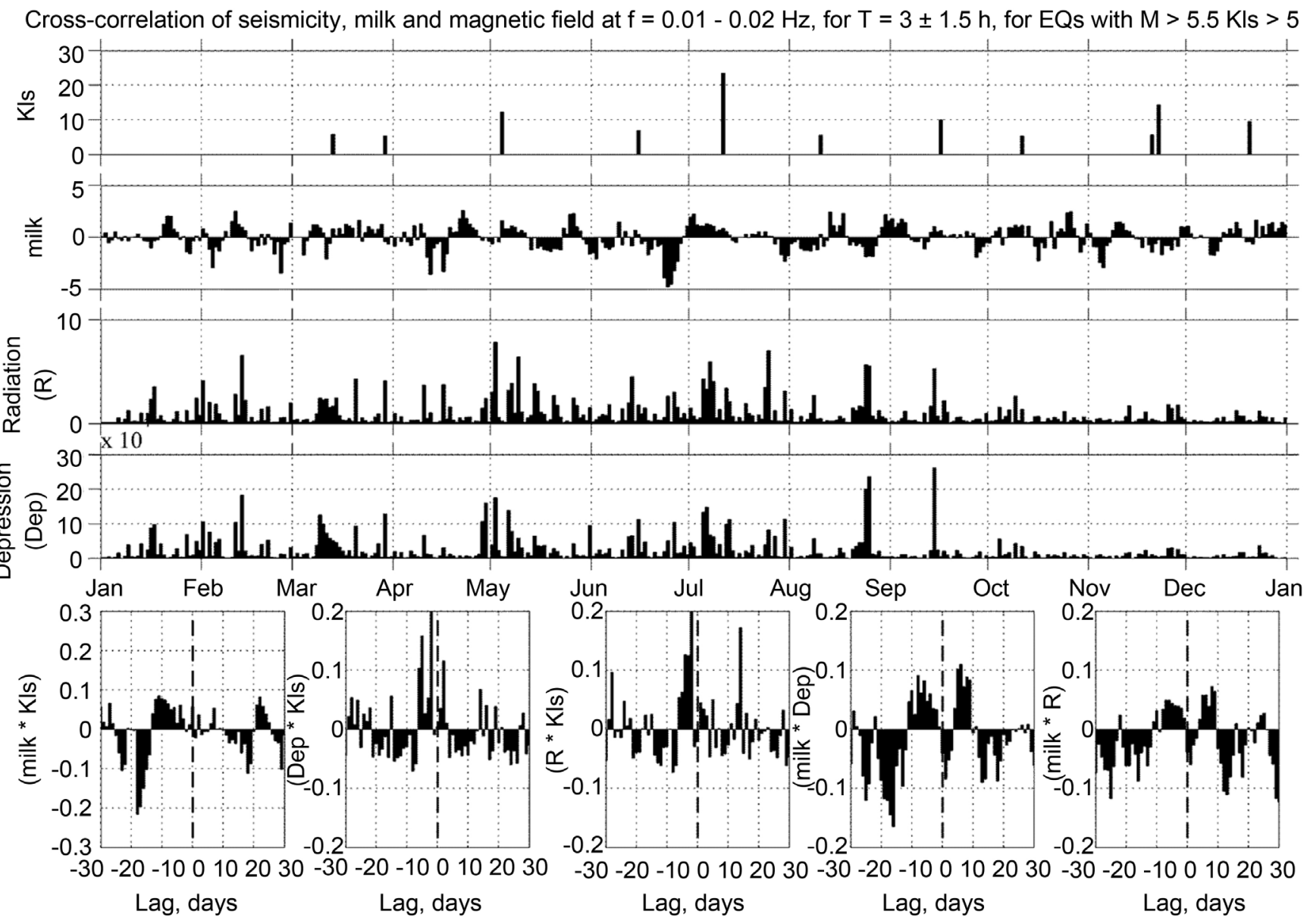

Figure 2. Temporal evolutions of seismicity (EQs, Kls), milk yield of cows, ULF radiation (with the use of polarization as the ratio of $Z$ to $\mathrm{H}$ components) and ULF depression (as the inverse of horizontal $\mathrm{H}$ component) are shown on the first top four panels. Five bottom panels indicate the superimposed epoch analysis of lag-correlograms of different combinations of those parameters. 
indicates that the milk yield is found to be depleted about 2 - 3 weeks before the EQ, though the cross-correlation coefficient is not so high. The second panel refers to the relationship of Dep versus Kls. This figure suggests a conspicuous tendency that the Dep (depression of $\mathrm{H}$ component) happens a few days to one week before the EQ. The third panel refers to the ULF radiation (R) vs. Kls. This figure suggests that there are a few significant peaks; 4 weeks, one week to a few days before the EQ, and about two weeks after the EQ. The fourth panel is concerned with the correlation between the milk yield and Dep, and the final fifth refers to the correlation between the milk yield of cows vs. the ULF radiation (R).

The temporal evolutions in Figure 2 suggest that the most significant effect of milk yield of cows (on the 2nd plot) is visibly observed in July in the vicinity of an EQ with maximum $\mathrm{Kls}$ index $(\mathrm{Kls}=23)$. It is also apparent that another successful case has happened in May, in such a way that the milk yield of cows showed a significant depletion before the EQ. On the other hand, it is clear from our previous experience that there are not noticeable responses of the milk yield of EQs with $\mathrm{Kl} l s 5$. So we will consider the most powerful events with the following characteristic of $M>6$. A map with such EQs is shown in Figure 3.

Only 3 EQs satisfied the conditions of both $\mathrm{M}>6$ and $\mathrm{Kls}>9.5$ as indicated in the top panel of Figure 4, which are found to be located in a close vicinity of the ULF station of KAK in Figure 3. The corresponding results are presented in Figure 4. When we compare this figure with Figure 2, it is found that the peak values of cross-correlation functions increased slightly for the 1st plot of milk vs. Kls and decreased for the plot of milk vs. ULF radiation as compared to those in the bottom panels of Figure 2, but they have approximately the same value for the plots of milk vs. ULF depression

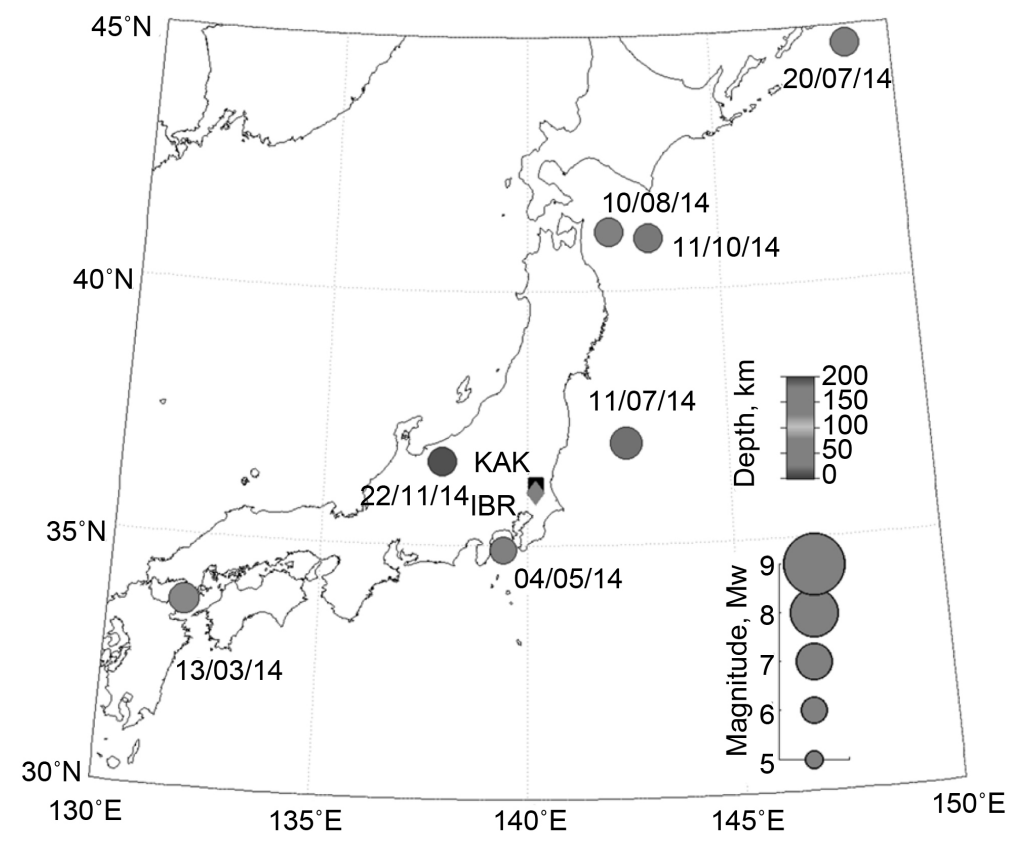

Figure 3. Map of the EQs with $M>6$. 


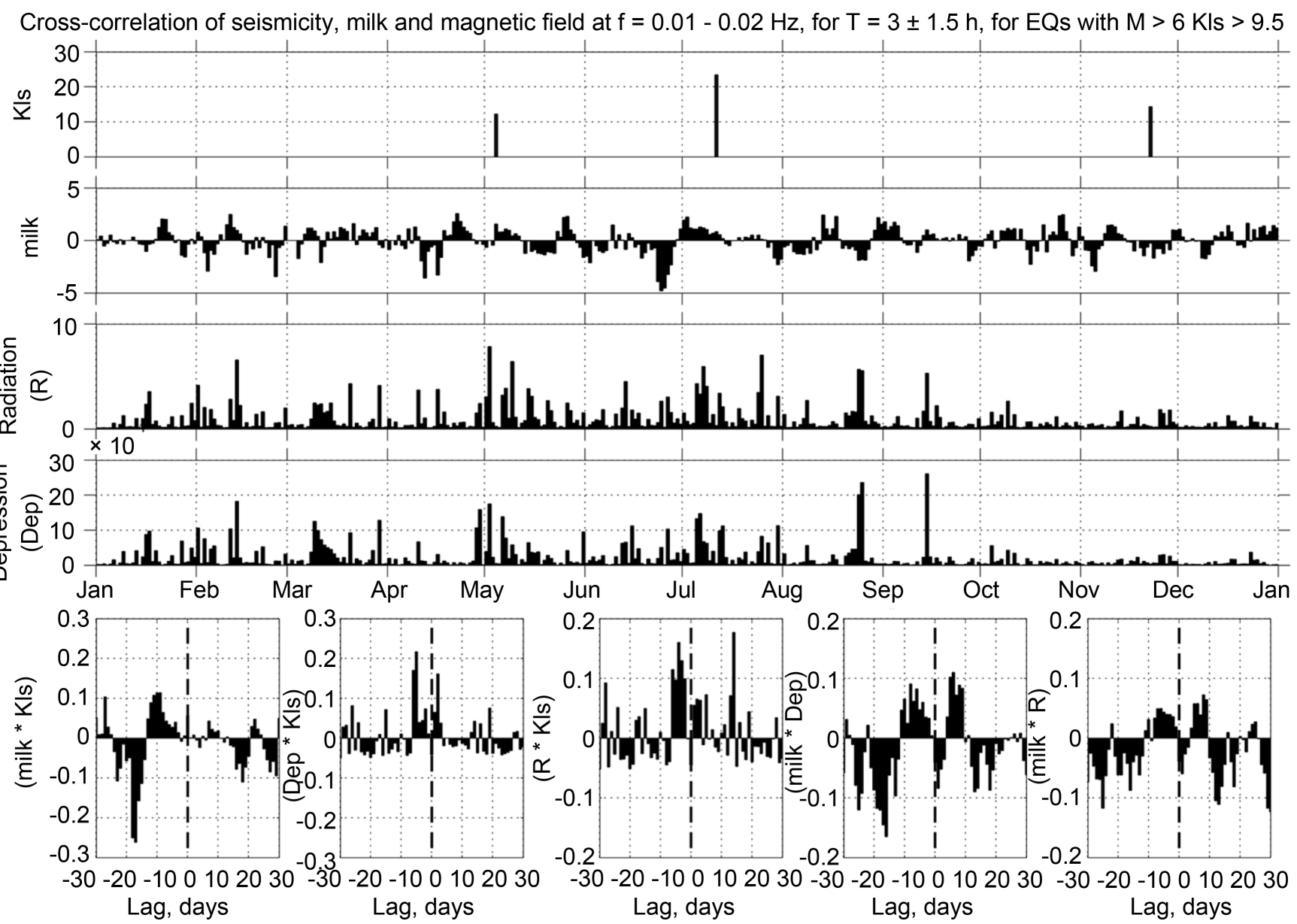

Figure 4. The same as Figure 2, but for larger EQs with $\mathrm{M}>6.0$ and Kls $>9.5$.

and for milk vs. ULF radiation.

Let us compare the bottom lag-correlograms in Figure 2 and Figure 4. Figure 2 refers to the condition of $M>5.5$ and Kls $>5$, while Figure 4 to the condition of $M>6$ and Kls $>9.5$ as the more condition of seismicity. This comparison might indicate that there is no significant change by changing the EQ condition. In Figure 2 we can identify a very clear (negative) peak (or depletion in milk yield of cows) at the lag time of 2 3 weeks. Also, the 2nd panel on Dep vs. Kls exhibits a clear positive peak about one week before the EQ and another peak at the lag of a few days after the EQ. This ULF depression is already known to be related with the lower ionospheric perturbations associated with EQs [29] [30], and the seismo-ionospheric perturbations are known to take place about one week before an EQ [9] [29]. On the other hand, the 3rd panel on R vs. Kls seems to show quite different behavior from the first two panels. There are a few positive peaks in the plots: one large positive peak (ULF radiation) appears a few days before the EQ, and other precursory peaks at time lags of 24 - 29 days and 15 - 19 days. Further, one large peak is seen about two weeks after the EQ, and a small peak just after the EQ. These might indicate that seismogenic ULF radiation tends to appear before an $\mathrm{EQ}$, but it happens in an extremely wide range of lead time from a few days to $\sim 30$ days. 
This long-lasting tendency of ULF radiation seems to be consistent with a recent statistical work by Hattori [13] with the use of ULF data at the same station of Kakioka.

Next two figures in both figures may be most important to know whether the ULF radiation (as suggested by Hayakawa [26]) is the main player of depletion of milk yield of cows. The fourth refers to the relationship between the milk yield and Dep (i.e., ionospheric perturbation), and the last is the direct correlation of milk yield and ULF radiation (R). As for these two figures, the peaks are meaningful, but their cross-correlation coefficients are small, anyway less than 0.2 , so that we cannot say any definite correlation between the change (or depletion) of milk yield of cows and any possible agents (ULF radiation, or ionospheric perturbations) only from these statistical plots based on the limited data.

So that, we try to examine the temporal evolutions of responses in milk yield of cows, ULF radiation (R), and ULF depression (Dep) \pm one month in the vicinity of those most powerful EQs on 4 May, 11 July, and 22 November 2014. The temporal evolutions of three parameters (top, milk yield of cows, second, ULF radiation (R), and bottom, ULF depression (Dep)) for each of 3 EQs are plotted in Figures 5-7. Figure 5 is the result for the EQ on 4 May, 2014, Figure 6 for the EQ on 11 July, 2014, and Figure 7, for the EQ on 22 November, 2014.

In order to find the possible sensory mechanism of abnormal animal behavior, we try to compare the temporal evolutions of three parameters in Figure 5 for the EQ ( $M=$ 6.0) on 4 May. The milk yield of cows is seen to be significantly depleted at the lead times around 22 days and 18 days before the EQ. The occurrence of seismogenic ULF radiation is found to be extremely widely distributed from -25 days to +30 days, with the main noticeable radiation seeming to be peaked a few days to about one week.

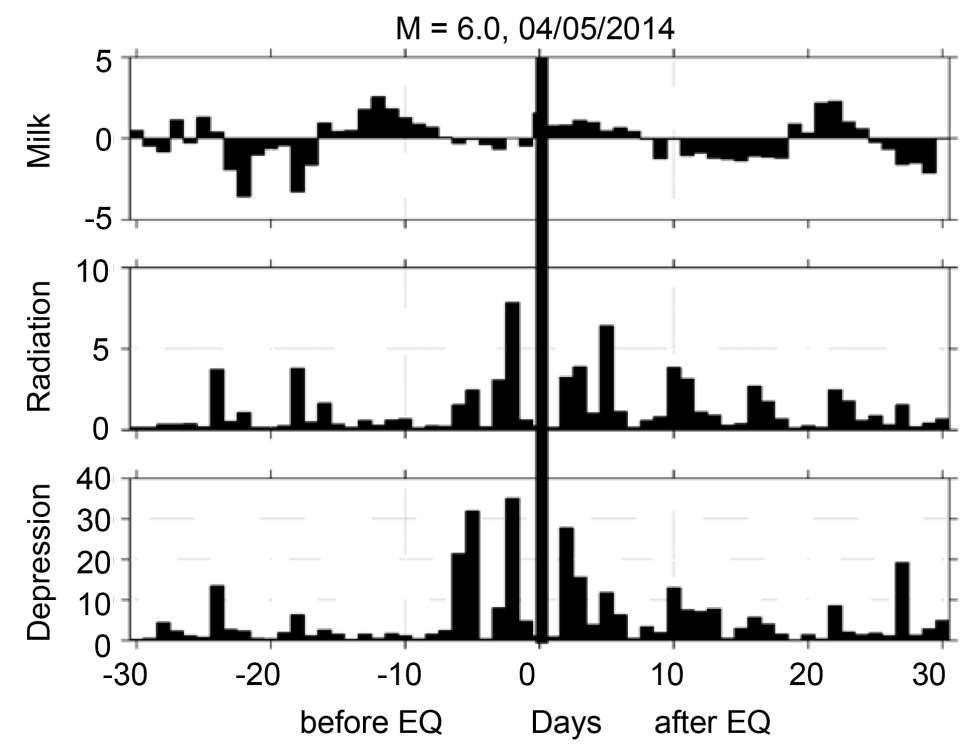

Figure 5. Temporal evolutions of milk yield of cows (top), ULF radiation (R) (second) and ULF depression (bottom) for the EQ $(M=6.0)$ on 4 May, 2014. 


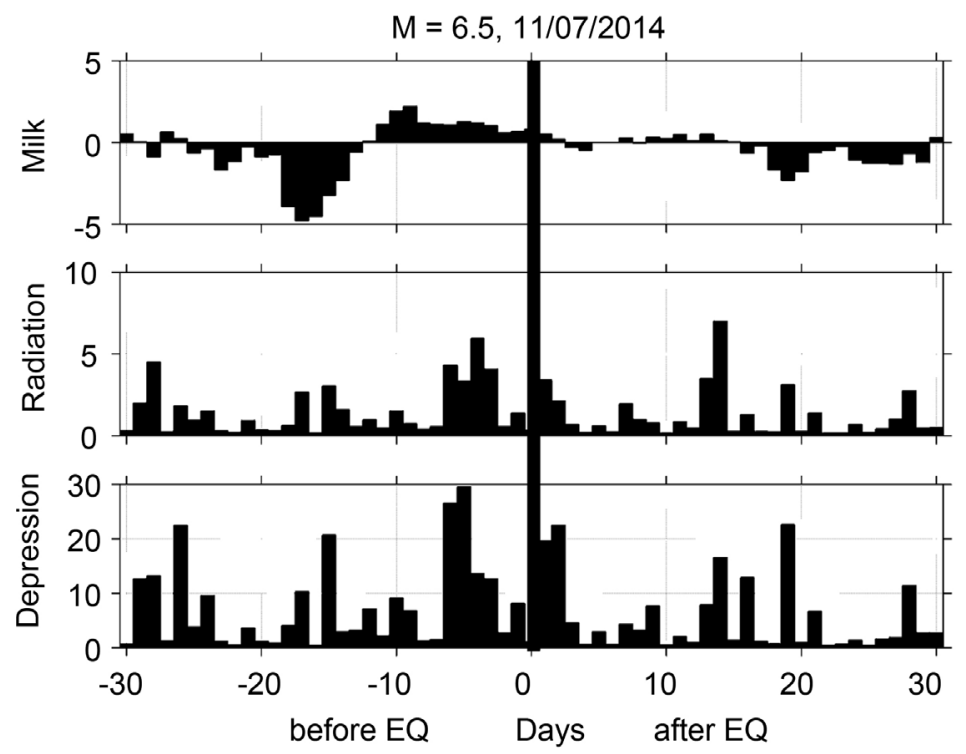

Figure 6. The same as Figure 5, but for the EQ $(M=6.5)$ on 11 July, 2014.

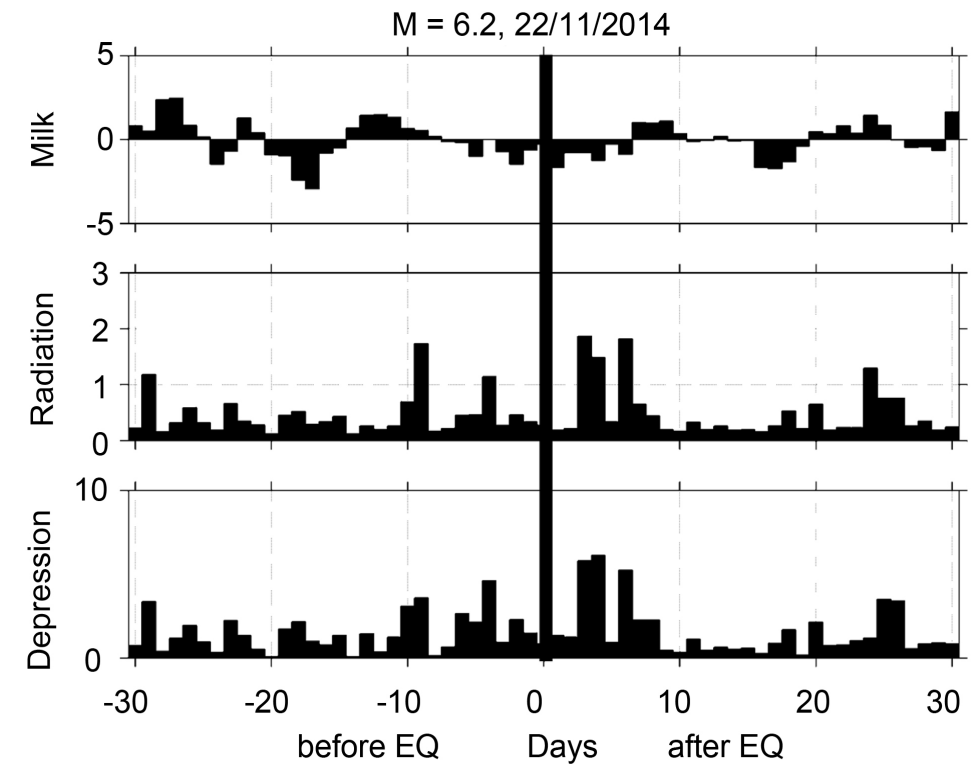

Figure 7. The same as Figure 6, but for the EQ $(M=6.2)$ on 22 November, 2014.

However, we can say that the time period of a decrease in milk yield of cows in the top panel is likely to overlap with the period of ULF radiation and some ULF depression (ionospheric perturbation). Then, we move on to Figure 6 for the next EQ $(M=6.5)$ on 11 July. The top panel of Figure 6 indicates a very conspicuous decrease in milk yield of cows in a time period from -18 to -14 days. Two electromagnetic effects (second panel on ULF radiation and third on ULF depression) are again seen to take place, at least, during the period of abnormal animal behavior, even though the main peaks for these two electromagnetic phenomena happen a few days to about one week before the EQ. 
Let us look at the last EQ $(M=6.2)$ on 22 November, 2014 in Figure 7. We can notice a depletion in milk yield of cows about 17 days before the EQ, but it is not so conspicuous as compared with the previous two cases in Figure 5 and Figure 6. Probably because of this insignificant decrease in milk yield of cows, no corresponding effects of electromagnetic effects are seen in the second and third panels.

\section{Conclusion and Discussion}

The followings have emerged from the present study on the basis of comparisons of data on milk yield of cows, seismicity, and ULF magnetic field variations during one particular year of 2014.

1) Clear responses seem to be observed for both the milk yield of cows and ULF magnetic field (both ULF radiation and ULF depression) for most powerful and not distant EQs with $M>6$, though the correlation coefficient is not so high.

2) Results could be more reliable for more powerful EQs.

3) The study on the direct correlation of milk yield of cows with ULF radiation/depression for major EQs may suggest that these two electromagnetic effects have happened, at least, during the period of depletion in milk yield of cows.

As already mentioned in Introduction, abnormal animal behavior is known to take place [2], but it seems that it is not yet statistically established. Once it is statistically correlated with EQs, it will be one important element of EQ prediction. For example, in the field of seismo-electromagnetics (i.e., electromagnetic phenomena (mainly precursors) associated with EQs), there appear some electromagnetic effects, which are statistically correlated with EQs on the basis of long-term observations. A few typical examples are 1) ionospheric perturbations, 2) ULF radiation, etc. The lower ionospheric perturbations have been found to be correlated with EQs based on long-term observations of subionospheric VLF/LF signal propagation [9]. These take place about one week before an EQ. The upper ionosphere such as F region is also found to be perturbed a few days to one week before an EQ [10]. However, the mechanism why and how the ionosphere is perturbed is not well understood (e.g., [1] [3] [34]). Further, it seems that there happens ULF electromagnetic radiation before a few famous EQs with magnitude greater than 7.0 (1988 Spitak EQ, 1989 Loma Prieta EQ, and 2003 Guam EQ) [1] [3], and a recent study [13] has summarized a statistical result that ULF radiation tends to appear before an EQ, which is based on the long-term (10 years) observation at the same station of Kakioka as studied in this paper. The present study has indicated a further confirmation on the basis of one-year extensive observation that clear responses are observed for both the milk yield of cows and ULF radiation/depression. The milk yield of cows is found to be depleted about 2 - 3 weeks before an EQ. This lead time is a little bit different from the first result on the milk yield of cows for the 2011 Tohoku EQ [25], in which the lead time was just one week. On the other hand, this paper suggests that ULF radiation is found to take place about one week before an EQ. This result seems to be slightly different form the corresponding results (2 - 3 weeks) for three famous major EQs with magnitude greater than 7.0 [3], and the result 
by Hattori [13] with the lead time in a wide range from a few days to one month.

The second objective of this paper was to investigate the sensory mechanism of abnormal animal behavior. A comparison of characteristics of abnormal animal behavior summarized in [2] with those of electromagnetic effects [1] [3] enabled us to suggest that ULF or ELF lower frequency radiation might be a possible candidate for abnormal animal behavior. So we have tried to make the direct correlation between the milk yield of cows and ULF radiation/depression. Detailed comparisons of temporal evolutions for three major EQs (with Kls > 9.5) have yielded that both effects of ULF radiation and ULF depression (ionospheric perturbations) are found to take place, at least, during the time period of a significant decrease in milk yield of cows. This finding suggests that we cannot deny our previous hypothesis that ULF radiation may be a possible sensory mechanism of abnormal animal behavior. Also ULF depression (as an indicator of lower ionospheric perturbations) happens during the period of abnormal animal behavior. Even though the major peak in ULF radiation happens about a few days to one week before the $\mathrm{EQ}$, the abnormal animal behavior is likely to take place in the initial phase of the occurrence of seismogenic ULF radiation. That is, animals seem to be sensitive to or react to the initial phase of seismogenic ULF radiation, and they get accustomed to the ULF radiation at later times even with more enhanced intensity one week before the EQ. A recent work for a major EQ $(M=7.2)$ by Grant et al. [35] has indicated that the abnormal animal behavior based on camera images of animals happens at the same time when they observed ionospheric perturbations with the use of subionospheric VLF propagation, and they have suggested that the positive-hole carriers during EQ preparation process [36] might be an important sensory mechanism of animals.

This paper is based only on one-year data, but there is a problem that the seismic activity (or EQ magnitude) is not so intensive in this particular year, and correspondingly the number of events is not large enough for a statistical study. Further accumulation of data events during a longer period at the relevant station and/or at other geological stations is highly required in order to reach a definite statistical conclusion on the abnormal animal behavior and its sensory mechanism.

\section{Acknowledgements}

We would like to thank the staffs of the Ibaraki Prefecture Livestock Experimental Station for providing us with the data on milk yield of cows.

\section{References}

[1] Hayakawa, M. (2015) Earthquake Prediction with Radio Techniques. John Wiley and Sons, Singapore. http://dx.doi.org/10.1002/9781118770368

[2] Rikitake, T. (2001) Predictions and Precursors of Major Earthquakes: The Science of MacroAnomaly Precursory to an Earthquake. Terra Scientific Publishing Company, Tokyo.

[3] Molchanov, O.A. and Hayakawa, M. (2008) Seismo Electromagnetics and Related Phenomena: History and Latest Results. TERRAPUB, Tokyo.

[4] Hayakawa, M., Ed. (2009) Electromagnetic Phenomena Associated with Earthquakes. Transworld Research Network, Trivandrum. 
[5] Hayakawa, M., Ed. (2012) The Frontier of Earthquake Prediction Studies. Nihonsenmontosho-Shuppan, Tokyo.

[6] Hayakawa, M., Ed. (2013) Earthquake Prediction Studies: Seismo Electromagnetics. TERRAPUB, Tokyo.

[7] Uyeda, S., Nagao, T. and Kamogawa, M. (2009) Short-Term Earthquake Prediction: Current State of Seismo-Electromagnetics. Tectonophysics, 470, 205-213. http://dx.doi.org/10.1016/j.tecto.2008.07.019

[8] Hayakawa, M. and Hobara, Y. (2010) Current Status of Seismo-Electromagnetics for Short-Term Earthquake Prediction. Geomatics, Natural Hazards and Risk, 1, 115-155. http://dx.doi.org/10.1080/19475705.2010.486933

[9] Hayakawa, M., Kasahara, Y., Nakamura, T., Muto, F., Horie, T., Maekawa, S., Hobara, Y., Rozhnoi, A.A., Solovieva, M. and Molchanov, O.A. (2010) A Statistical Study on the Correlation between Lower Ionospheric Perturbations as Seen by Subionospheric VLF/LF Propagation and Earthquakes. Journal of Geophysical Research, 115, A09305.

[10] Liu, J.Y. (2009) Earthquake Precursors Observed in the Ionospheric F-Region. In: Hayakawa, M., Ed., Electromagnetic Phenomena Associated with Earthquakes, Transworld Research Network, Trivandrum, 187-204.

[11] Hayakawa, M., Hattori, K. and Ohta, K. (2007) Monitoring of ULF (Ultra-Low-Frequency) Geomagnetic Variations Associated with Earthquakes. Sensors, 7, 1108-1122. http://dx.doi.org/10.3390/s7071108

[12] Hayakawa, M., Hobara, Y., Ohta, K. and Hattori, K. (2011) The Ultra-Low-Frequency Magnetic Disturbances Associated with Earthquakes. Earthquake Science, 24, 523-534. http://dx.doi.org/10.1007/s11589-011-0814-2

[13] Hattori, K. (2013) ULF Geomagnetic Changes Associated with Major Earthquakes. In: Hayakawa, M., Ed., Earthquake Prediction Studies: Seismo-Electromagnetics, TERRAPUB, Tokyo, 129-152.

[14] Evernden, J. (1976) U.S. Geological Survey Office of Earthquake Studies. Abnormal Animal Behavior Prior to Earthquakes. U.S. Department of Commerce, National Technical Information Service, Alexandria.

[15] Buskirk, R.E., Frohlich, C. and Lantham, G.V. (1981) Unusual Animal Behavior before Earthquakes: A Review of Possible Sensory Mechanisms. Reviews of Geophysics, 19, 247 270. http://dx.doi.org/10.1029/RG019i002p00247

[16] Tributsch, H. (1982) When the Snakes Awake-Animals and Earthquake Prediction. MIT Press, Cambridge, USA.

[17] Kirschvink, J.L. (2000) Earthquake Prediction by Animals: Evolution and Sensory Perception. Bulletin of the Seismological Society of America, 90, 312-323. http://dx.doi.org/10.1785/0119980114

[18] Ikeya, M. (2004) Earthquakes and Animals: From Folk Legends to Science. World Scientific, Singapore. http://dx.doi.org/10.1142/5382

[19] Yokoi, S., Ikeya, M., Yagi, T. and Nagai, K. (2003) Mouse Circadian Rhythm before the Kobe Earthquake in 1995. Bioelectromagnetics, 24, 289-291.

http://dx.doi.org/10.1002/bem.10108

[20] Li, Y., Liu, Y., Jiang, Z., Guan, J., Yi, G., Cheng, S., Yang, B., Fu, T. and Wang, Z. (2009) Behavioral Change Related to Wenchuan Devastating Earthquake in Mice. Bioelectromagnetics, 30, 613-620. http://dx.doi.org/10.1002/bem.20520

[21] Bhargava, N., Katiyar, V.K., Sharma, M.L. and Pradhan, P. (2009) Earthquake Prediction through Animal Behavior: A Review. Indian Journal of Biomechanics, 7-8, 159-165. 
[22] Grant, R.A. and Halliday, T. (2010) Predicting the Unpredictable: Evidence of Pre-Seismic Anticipatory Behavior in the Common Toad. Journal of Zoology, 281, 263-271.

[23] Nishimura, T., Okano, H., Tada, H., Nishimura, E., Sugimoto, K., Mohri, K. and Fukushima, M. (2010) Lizards Respond to an Extremely Low-Frequency Electromagnetic Field. Journal of Experimental Biology, 213, 1985-1990. http://dx.doi.org/10.1242/jeb.031609

[24] Grant, R.A., Halliday, T., Balderer, W.P., Leuenberger, F., Newcomer, M., Cyr, G. and Freund, F.T. (2011) Ground Water Chemistry Changes before Major Earthquakes and Possible Effects on Animals. International Journal of Environmental Research and Public Health, 8, 1936-1959. http://dx.doi.org/10.3390/ijerph8061936

[25] Yamauchi, H., Uchiyama, H., Ohtani, N. and Ohta, M. (2014) Unusual Animal Behavior Preceding the 2011 Earthquake off the Pacific Coast of Tohoku, Japan: A Way to Predict the Approach of Large Earthquake. Animals, 4, 131-145. http://dx.doi.org/10.3390/ani4020131

[26] Hayakawa, M. (2013) Possible Electromagnetic Effects on Abnormal Animal Behavior before an Earthquake. Animals, 3, 19-32. http://dx.doi.org/10.3390/ani3010019

[27] National Oceanic and Atmospheric Administration (NOAA) (1976) Livestock Hot Weather stress. Operations Manual Letter C-31-76. Department of Commerce, NOAA, National Weather Service Central Region, Kansas City.

[28] Vitali, A., Segnalini, M., Bertocchi, L., Bernabucci, U., Nardone, A. and Lacetera, N. (2009) Seasonal Pattern of Mortality and Relationships between Mortality and Temperature-Humidity Index in Dairy Cows. Journal of Dairy Science, 92, 3781-3790. http://dx.doi.org/10.3168/jds.2009-2127

[29] Schekotov, A., Molchanov, O., Hattori, K., Fedorov, E., Gladyshev, V.A., Belyaev, G.G., Chebrov, V., Sinitsin, V., Gordeev, E. and Hayakawa, M. (2006) Seismo-Ionospheric Depression of the ULF Geomagnetic Fluctuations at Kamchatka and Japan. Physics and Chemistry of the Earth, Parts $A / B / C, 31,313-318$. http://dx.doi.org/10.1016/j.pce.2006.02.043

[30] Schekotov, A., Fedorov, E., Molchanov, O.A. and Hayakawa, M. (2013) Low Frequency Electromagnetic Precursors as a Prospect for Earthquake Prediction. In: Hayakawa, M. Ed., Earthquake Prediction Studies: Seismo-Electromagnetics, TERRAPUB, Tokyo, 81-99.

[31] Hayakawa, M., Kawate, R., Molchanov, O.A. and Yumoto, K. (1996) Results of Ultra-LowFrequency Magnetic Field Measurements during the Guam Earthquake of 8 August 1993. Geophysical Research Letters, 23, 241-244. http://dx.doi.org/10.1029/95GL02863

[32] Currie, J.L. and Waters, C.L. (2014) On the Use of Geomagnetic Indices and ULF Waves for Earthquake Precursor Signatures. Journal of Geophysical Research: Space Physics, 119, 9921003. http://dx.doi.org/10.1002/2013JA019530

[33] Hayakawa, M., Rozhnoi, A., Solovieva, M., Hobara, Y., Ohta, K., Schekotov, A. and Fedorov, E. (2013) The Lower Ionospheric Perturbation as a Precursor to the 11 March 2011 Japan Earthquake. Geomatics, Natural Hazards and Risk, 4, 275-287.

[34] Pulinets, S.A. and Boyarchuk, K. (2004) Ionospheric Precursors of Earthquakes. Springer, Berlin.

[35] Grant, R., Raulin, J.P. and Freund, F.T. (2015) Changes in Animal Activity Prior to a Major $(\mathrm{M}=7)$ Earthquake in the Peruvian Andes. Physics and Chemistry of the Earth, Parts $A / B / C, 85-86,69-77$. http://dx.doi.org/10.1016/j.pce.2015.02.012

[36] Freund, F.T. (2009) Stress-Activated Positive Hole Charge Carriers in Rocks and the Generation of Pre-Earthquake Signals. In: Hayakawa, M. Ed., Electromagnetic Phenomena Associated with Earthquakes, Transworld Research Network, India, 41-96. 
Submit or recommend next manuscript to SCIRP and we will provide best service for you:

Accepting pre-submission inquiries through Email, Facebook, LinkedIn, Twitter, etc. A wide selection of journals (inclusive of 9 subjects, more than 200 journals)

Providing 24-hour high-quality service

User-friendly online submission system

Fair and swift peer-review system

Efficient typesetting and proofreading procedure

Display of the result of downloads and visits, as well as the number of cited articles

Maximum dissemination of your research work

Submit your manuscript at: http://papersubmission.scirp.org/

Or contact ojer@scirp.org 